BMJ Open Sport \& Exercise Medicine

\title{
Effects of the lower jaw position on athletic performance of elite athletes
}

\author{
John Patrick Haughey (1D, Peter Fine
}

To cite: Haughey JP, and Fine $P$, Effects of the lower jaw position on athletic performance of elite athletes. BMJ Open Sport \& Exercise Medicine 2020;0:e000886. doi:10.1136/bmjsem-2020 000886

- Supplemental material is published online only. To view please visit the journal online (http://dx.doi.org/10.1136/ bmjsem-2020-000886).

Accepted 10 November 2020
Check for updates

(C) Author(s) (or their employer(s)) 2020. Re-use permitted under CC BY-NC. No commercial re-use. See rights and permissions. Published by BMJ.

CPD, UCL Eastman Dental Institute, London, UK

Correspondence to John Patrick Haughey; j.haughey@ucl.ac.uk

\section{ABSTRACT}

When an athlete wears a mouthguard, the position of the lower jaw is changed by virtue of the teeth being unable to occlude. Little research is available in in this area, which have indicated both positive impact and no positive impact. Objectives This study aims to explore the influence of the lower jaw position on athletic performance in elite athletes. Methods A repeated measures study compared two lower jaw positions, the athlete's normal (habitual) bite and the lower jaw position when the muscles of mastication are at physiological rest (physiological rest bite). 15 athletes completed a medicine ball putt (upper body power), vertical jump (lower body power), sit and reach (composite hamstring flexibility), passive knee flexion (hamstring muscle length) and star excursion balance (stability and balance) tests in each condition.

Results Paired t-tests showed the physiological rest bite had significant $(p<0.05)$ positive effect on athletic

performance for each test. On average the physiological rest bite provided an increase of lower body power (5.8\%), upper body power (10\%), hamstring flexibility (14\%) and balance and stability (4.8\%) compared to the habitual bite.

Conclusion This study provides evidence of the need for further research to confirm if the lower jaw position can be optimised for athletic performance in athletes.

\section{INTRODUCTION}

Current research suggests the risk of orofacial sports injury is 1.6-1.9 times higher when a mouthguard is not worn. ${ }^{1}$ Unlike protective abilities, current research has not led to a consensus on whether mouthguard use can impact performance. The general conclusion is a properly designed and fitted mouthguard has no negative impact on athletic performance. $^{2}$ Some research showed positive impacts on performance ${ }^{3}$ with suggestions that the position of the lower jaw influences athletic performance. ${ }^{4}$

There appears to be an issue in the current research due to inconsistency in the type of mouthguard used. A mouthguard when worn changes the oral environment by taking up free space in the mouth and changing the position of the lower jaw by not allowing the lower teeth to occlude with the upper teeth.

This research aims to evaluate if the position of the lower jaw can affect athletic performance.

\section{Summary}

Lower jaw position may affect athletic performance.

- Physiological rest lower jaw position showed significant improvements in power, hamstring flexibility and balance and stability.

- Suggests the lower jaw position of athletes can be optimised for athletic performance.

Three athletic attributes were tested (power, flexibility and balance\&stability) to compare two lower jaw positions, the athlete's habitual (normal) bite and the lower jaw position when the muscles of mastication are at physiological rest (physiological rest bite).

\section{METHODS}

\section{Study design}

A repeated measures study was undertaken as this study type can provide a more definitive evaluation of within-person change across time. ${ }^{5}$

\section{Different testing conditions}

Two different jaw positions were tested, the athlete's habitual bite(HB) without a mouthguard in place and the mouthguard (physiological rest position) bite. The HB was determined by the athlete biting their teeth together normally. The mouthguard bite(MB) was determined by instructing the athlete to bite into the mouthguard.

The principles of neuromuscular occlusion were used to find the physiological rest lower jaw position (PRLJP). ${ }^{6}$ An ultra-low frequency transcutaneous electrical nerve stimulation (ULF-TENS) device was used to relax the muscles of mastication and using surface electromyography (sEMG) to measure electrical activity of the muscles of mastication, in particular the temporalis and masseter muscles, a lower jaw position was recorded that correlated to the PRLJP of the muscles of mastication.

A custom-fitted, pressurised, thermoforming maxillary mouthguard was then made at the recommended thickness for the athlete's sport, trimmed to ensure no negative effect 
and the occlusal surface prepared to allow the opposing lower teeth to occlude comfortably. The position of the lower jaw when biting into the mouthguard replicated the recorded PRLJP.

\section{Sample group}

The athletes were either elite amateur or professional athletes from sports where mouthguard use is common practice; Gaelic football, Field Hockey and Boxing. 15 athletes took part in the testing who were injury-free, healthy and had no temporomandibular joint pain or symptoms.

\section{Setting}

Athletes attended two sessions, the first at a dental surgery for dental impressions and recording of the PRLJP allowing mouthguard fabrication. The second session at a gym environment for athletic performance testing.

\section{Testing}

Three athletic attributes were tested (power, flexibility and balance\&stability). Tests were chosen for reliability, sport specificity and ease to conduct at different locations.

Power was selected due to the correlation of power output and sports performance.

\section{Lower body power}

A standard countermovement Vertical Jump (VJ) using a digital jump mat, 'Just Jump System', to record results assessed lower body power. Three test jumps were recorded for each condition with the mean used as the test score.

\section{Upper body power}

A Seated Medicine Ball Putt(BP $)^{7}$ using a $9 \mathrm{~kg}$ medicine ball and an inclined bench press was used to assess upper body power. Each athlete did three sub-maximal practice throws. The mean throw distance of the three test scores was used.

2-minute rest periods were used to allow recovery between power tests. ${ }^{8}$

Hamstring injuries are one of the most common reoccurring sporting injuries ${ }^{9}$ with a negative impact on performance. Hamstring flexibility is an important factor associated with hamstring injuries. ${ }^{10} 11$

The sit-and-reach(SR) test ${ }^{12}$ was used as a composite test and scored by the most distant point on The MAT (Movement Assessment Tool by Movement Assessment
Technologies) reached by both hands. The passive knee extension(PKE) test was used as an isolated muscle length test and scored by the maximum degree of flexion achieved.

Balance \& stability was selected due to the proximity of the temporomandibular joint (TMJ) and the balance control systems in the ear. The posteromedial directional movement ${ }^{13}$ with each leg in the Star Excursion Balance Test (SEBT) was tested using the MAT to determine balance\&stability. The athletes did six practice trials ${ }^{14}$ before testing each leg.

To eliminate influence from repetition or fatigue on the test results, the athletes completed the tests in a randomised condition order. Eight athletes completed testing in $\mathrm{HB}$ then repeated in $\mathrm{MB}$ and seven athletes did the opposite order.

\section{Data analysis}

Sample size was 15 . The ratio data meant a parametric test was needed. No test for homogeneity of variance was required as only one group was involved. As the study was a series of repeated measures tests within subjects of two conditions, paired t-tests were used to compare the results. The data were assessed to ensure it met the assumption, for a paired t-test, of being normally distributed.

\section{RESULTS}

Shapiro-Wilk statistic showed the data collected for each test met the assumption of being normally distributed, $p>0.05$. A paired samples t-test was conducted to compare the data for each test condition, $\mathrm{HB}$ and $\mathrm{MB}$, from the VJ, BP, SEBT, SR and PKF tests. The results are provided in the online supplemental material. A summary of the results is displayed in Table 1 . The paired sample t-tests showed that the change in the lower jaw position created by MB had a significant positive effect, $\mathrm{p}<0.05$, for each athletic test.

Reviewing the test means, figure 1 , the MB provided an improvement in lower body power of $5.8 \%$, upper body power of $10 \%$, hamstring flexibility of $14 \%$ and balance and stability of $4.8 \%$ compared to the HB.

\section{DISCUSSION}

This research aimed to answer the question-does the position of the lower jaw affect athletic performance? The results strongly suggest that the lower jaw position

Table 1 Summary of results

\begin{tabular}{|c|c|c|c|c|c|c|c|}
\hline $\begin{array}{l}\text { Performance } \\
\text { testing }\end{array}$ & $\begin{array}{l}\text { Lower Body } \\
\text { Power (VJ) }\end{array}$ & $\begin{array}{l}\text { Upper Body } \\
\text { Power (BP) }\end{array}$ & $\begin{array}{l}\text { Hamstring } \\
\text { flexibility } \\
\text { Sit and } \\
\text { Reach (SR) }\end{array}$ & $\begin{array}{l}\text { Hamstring } \\
\text { flexibility } \\
\text { Passive Knee } \\
\text { flexion (PKF) } \\
\text { Right leg }\end{array}$ & $\begin{array}{l}\text { Hamstring } \\
\text { flexibility } \\
\text { Passive Knee } \\
\text { flexion (PKF) } \\
\text { Left leg }\end{array}$ & $\begin{array}{l}\text { Balance \& } \\
\text { stability } \\
\text { (SEBT) } \\
\text { Right leg }\end{array}$ & $\begin{array}{l}\text { Balance \& } \\
\text { stability } \\
\text { (SEBT) } \\
\text { Left leg }\end{array}$ \\
\hline p Value & $<0.05$ & $<0.05$ & $<0.05$ & $<0.05$ & $<0.05$ & $<0.05$ & $<0.05$ \\
\hline Habitual bite & $\begin{array}{l}M=46.29 \mathrm{~cm} \\
S D=6.44\end{array}$ & $\begin{array}{l}M=255.49 \mathrm{~cm} \\
S D=53.6\end{array}$ & $\begin{array}{l}M=51.6 \mathrm{~cm} \\
\mathrm{SD}=11.92\end{array}$ & $\begin{array}{l}M=47.2^{\circ} \\
S D=11.03\end{array}$ & $\begin{array}{l}M=45.47^{\circ} \\
S D=9.36\end{array}$ & $\begin{array}{l}M=85.07 \mathrm{~cm} \\
S D=7.49\end{array}$ & $\begin{array}{l}\mathrm{M}=84.27 \mathrm{~cm} \\
\mathrm{SD}=7.77\end{array}$ \\
\hline $\begin{array}{l}\text { Mouthguard } \\
\text { bite }\end{array}$ & $\begin{array}{l}M=48.97 \mathrm{~cm} \\
\mathrm{SD}=6.57\end{array}$ & $\begin{array}{l}M=281.08 \mathrm{~cm} \\
S D=58.22\end{array}$ & $\begin{array}{l}M=55.07 \mathrm{~cm} \\
\mathrm{SD}=11.44\end{array}$ & $\begin{array}{l}M=56.4^{\circ} \\
S D=11.52\end{array}$ & $\begin{array}{l}M=52.73^{\circ} \\
S D=9.37\end{array}$ & $\begin{array}{l}M=88.87 \mathrm{~cm} \\
S D=7.14\end{array}$ & $\begin{array}{l}M=88.5 \mathrm{~cm} \\
S D=7.58\end{array}$ \\
\hline
\end{tabular}




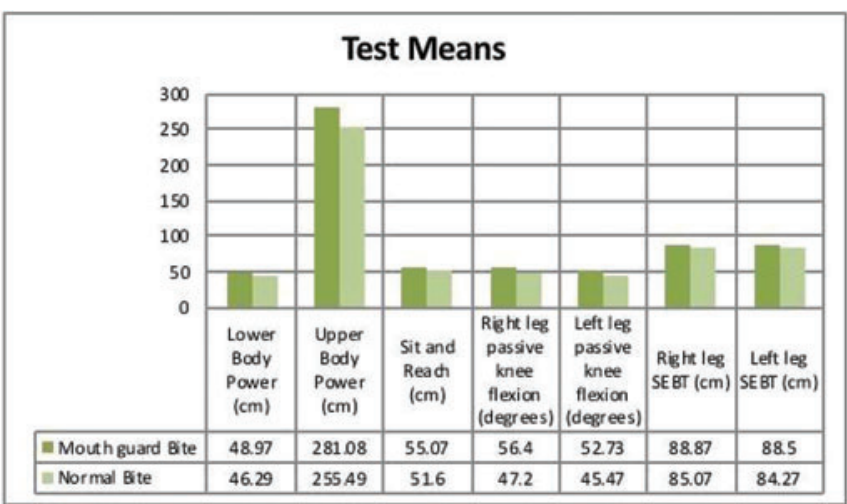

Figure 1 Comparison of mean test results.

influences athletic power, hamstring flexibility and balance\&stability.

\section{Limitations}

i. Assessing the athlete's current mouthguard was considered but the inconsistency in mouthguard type and inability to define the lower jaw position made this unachievable.

ii. Some tests were dependent on the researcher confirming the score, a potential bias.

iii. The small sample size $(n=15)$ was due to intensive schedules of elite athletes with the majority competing internationally and each of the two sessions requiring 2 hours of the athlete's time.

\section{Comparisons to previous research}

The hamstring muscle changes and the improvements in power observed are consistent with previous research ${ }^{15}$ and support previous findings ${ }^{16}$ that a maxillary appliance has an influence on the rate of force development and maximal strength. This current research contradicts the view of past researchers who stated a mouthguard has no effect on performance ${ }^{317}$ and provides evidence supporting the need for muscular performance assessments to be planned with the mouthguard being worn. ${ }^{18}$

\section{Explanation of observations}

A mouthguard has two influences on the oral environment, free space in the mouth and lower jaw position. The mouthguards used in this study were designed to have a minimal negative impact on free space available for tongue posture. The PRP in the mouthguard allowed the muscles of mastication to function optimally from their full resting length. ${ }^{19}$ Compared to their $\mathrm{HB}$, the $\mathrm{MB}$ in every athlete was more vertical and anterior creating more free space and causing TMJ decompression (See figure 2). By creating free space, this allows the tongue to posture in a more anterior position increasing upper airway space (See figure 2).

The increased airway space changes cervical spine curvature by reducing forward head posture (See figure 2). The muscle chains concept (See figure 3$)^{20}$ on how one link not operating efficiently changes function and structure

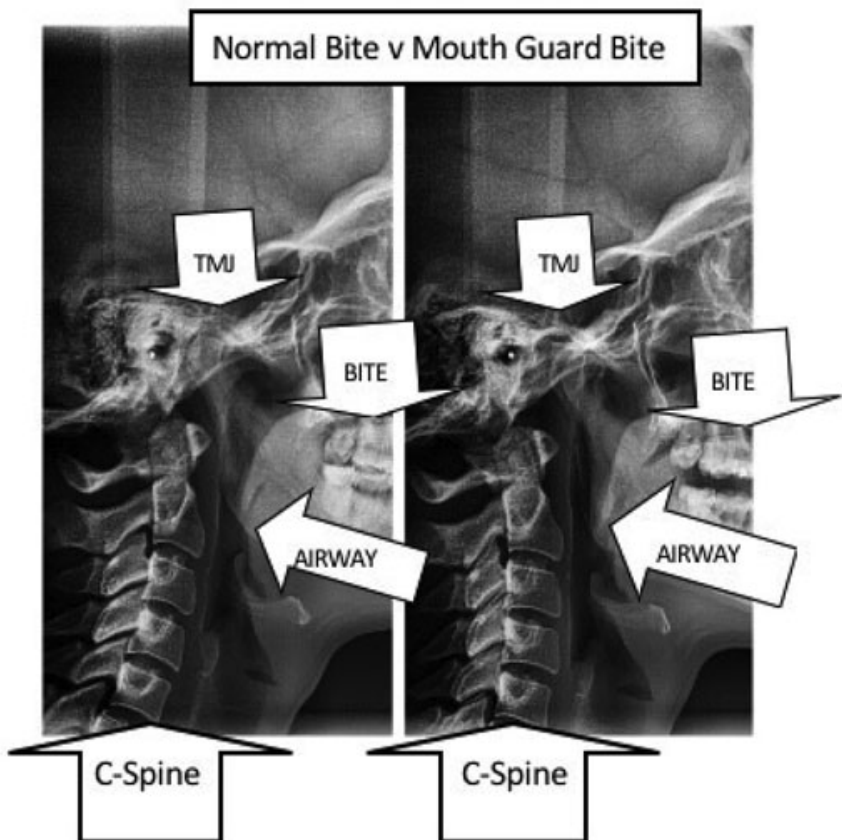

Figure 2 Comparison between habitual bite and mouthguard bite in an athlete using radiography.

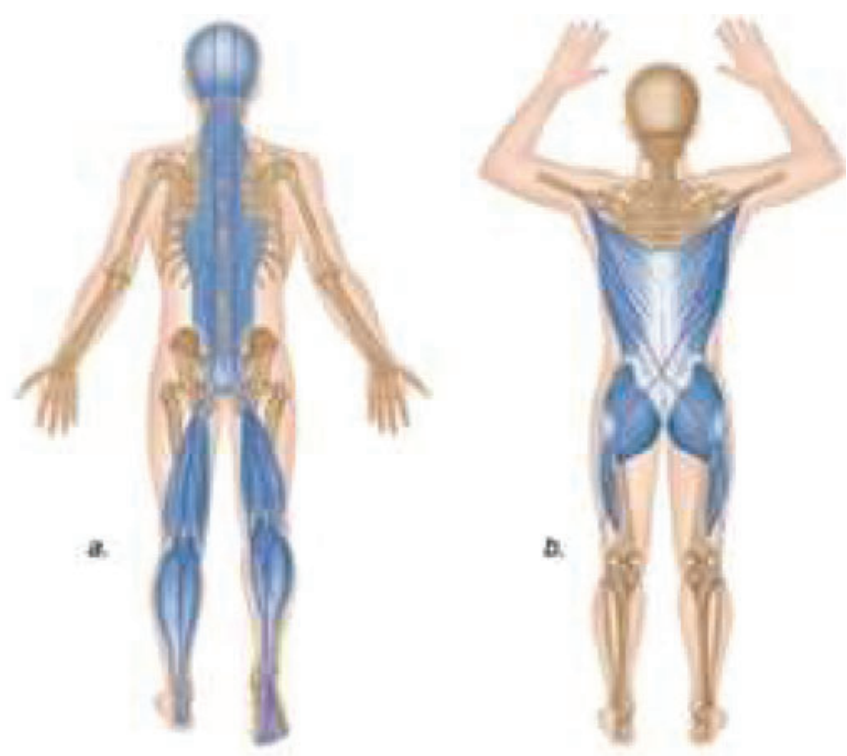

Figure 3 'The posterior chain' the main muscle chain responsible for keeping the human body upright. ${ }^{20}$

throughout the chain ${ }^{21}$ could explain how the lower jaw position can influence the musculature not directly corrected to the lower jaw, for example, the hamstring muscles.

The physiological change in head and neck created by the MB removes any lesser effect of the HB.

The muscles contracting from their full resting length and the improved head posture would help explain the improvement in athletic performance observed in this study. 


\section{Recommendations for future research}

Due to the lack of research in this area, further studies are needed to investigate how the lower jaw position influences performance. It would be interesting to repeat the study with a larger cohort and under varying conditions with respect to the different standards of mouthguards worn.

\section{CONCLUSION}

Mouthguards are generally made and worn for protective purposes, designed to be a certain thickness to help protect the teeth and oral cavity from trauma with little or no consideration given to the lower jaw position created by the athlete when worn. This study provides evidence of the need for further research on the lower jaw position of athletes. The lower jaw position during athletic performance will differ depending on whether it is formed by the habitual bite, the bite created by wearing a protective mouthguard, or the bite created by wearing a mouthpiece that is being promoted as performance enhancing. Further research is needed to confirm if the lower jaw position can be optimised to get a positive effect on athletic performance.

Twitter John Haughey @sportingsmiles1.

Acknowledgements The authors would like to express their appreciation to all the athletes who took time out of their busy schedules to take part in this research and to the athlete support teams who provided access to training facilities for carrying out the research. The lead author, Dr John Haughey, would like to express his gratitude to University of Chester tutors Professor Stephen Fallows and John Sharkey for their support and guidance in developing this research as part of his Masters thesis, http://hdl.handle.net/10034/622079.

Contributors $\mathrm{JH}$ designed the study, performed the testing, analysed the data and wrote the paper with input from all authors. PF contributed to the analysis of the results and to the writing of the manuscript.

Funding The research was self-funded by the researcher.

Competing interests None declared.

Ethics approval Name: University of Chester, Faculty of Life Sciences, Research Ethics Committee number/ID: 1063/15/JH/CSN.

Provenance and peer review Not commissioned; externally peer reviewed.

Supplemental material This content has been supplied by the author(s). It has not been vetted by BMJ Publishing Group Limited (BMJ) and may not have been peerreviewed. Any opinions or recommendations discussed are solely those of the author(s) and are not endorsed by BMJ. BMJ disclaims all liability and responsibility arising from any reliance placed on the content. Where the content includes any translated material, BMJ does not warrant the accuracy and reliability of the translations (including but not limited to local regulations, clinical guidelines, terminology, drug names and drug dosages), and is not responsible for any error and/or omissions arising from translation and adaptation or otherwise.

Open access This is an open access article distributed in accordance with the Creative Commons Attribution Non Commercial (CC BY-NC 4.0) license, which permits others to distribute, remix, adapt, build upon this work non-commercially, and license their derivative works on different terms, provided the original work is properly cited, appropriate credit is given, any changes made indicated, and the use is non-commercial. See: http://creativecommons.org/licenses/by-nc/4.0/.

ORCID iD

John Patrick Haughey http://orcid.org/0000-0002-7169-0948

\section{REFERENCES}

1 Knapik JJ, Marshall SW, Lee RB, et al. Mouthguards in sport activities. Sports Med 2017;37:117-44.

2 Von Arx T, Flury R, Tschan J, et al. Exercise capacity in athletes with mouthguards. Int J Sports Med 2008;29:435-8.

3 Morales J, Buscà B, Solana-Tramunt M, et al. Acute effects of jaw clenching using a customized mouthguard on anaerobic ability and ventilatory flows. Hum Mov Sci 2015;44:270-6.

4 Maurer C, Heller S, Sure J-J, et al. Strength improvements through occlusal splints? The effects of different lower jaw positions on maximal isometric force production and performance in different jumping types. PLoS One 2018;13:e0193540.

5 Guo Y, Logan HL, Glueck DH, et al. Selecting a sample size for studies with repeated measures. BMC Med Res Methodol 2013;13:1.

6 Cooper B, Kleinberg I. Establishment of a temporomandibular physiological state with neuromuscular orthosis treatment affects reduction of TMD symptoms in 313 patients. $J$ Craniomandibular Pract 2008;26:104-17.

7 Clemons JM, Campbell B, Jeansonne C. Validity and reliability of a new test of upper body power. J Strength Condition Res 2010:24:1578-1565.

8 Miller T. NSCA's guide to tests and assessments. Chicago, USA: Human Kinetics, Sheridan Books, 2012.

9 Petersen J, Hölmich P. Evidence based prevention of hamstring injuries in sport. Br J Sports Med 2005;39:319-23.

10 Witvrouw E, Danneels L, Asselman P, et al. Muscle flexibility as a risk factor for developing muscle injuries in male professional soccer players. A prospective study. Am J Sports Med 2003;31:41-6.

11 Dadebo B, White J, George KP. A survey of flexibility training protocols and hamstring strains in professional football clubs in England. $\mathrm{Br}$ J Sports Med 2004;38:388-94.

12 Baltaci G, Un N, Tunay V, et al. Comparison of three different sit and reach tests for measurement of hamstring flexibility in female university students. Br J Sports Med 2003;37:59-61.

13 Olmsted-Kramer LC. Simplifying the star excursion balance test: analyses of subjects with and without chronic ankle instability. J Orthopaedic Sports Phys Therapy 2006.

14 Kinzey SJ, Armstrong CW. The reliability of the star-excursion test in assessing dynamic balance. J Orthopaedic Sports Phys Therapy 1998:27:356-60.

15 Cetin C, Keçeci AD, Erdoğan A, et al. Influence of custom-made mouth guards on strength, speed and anaerobic performance of taekwondo athletes. Dental Traumatol 2009;25:272-6.

16 Maurer $\mathrm{C}$, Stief $\mathrm{F}$, Jonas $\mathrm{A}$, et al. Influence of the lower jaw position on the running pattern. PLoS One 2015;10:e0135712.

17 Bourdin M, Brunet-Patru I, Hager P, et al. Influence of maxillary mouthguards on physiological parameters. Med Sci Sports Exerc 2006;38:1500-4.

18 Grosdent S, O'Thanh R, Domken O, et al. Dental occlusion influences knee muscular performances in asymptomatic females. $J$ Strength Condition Res 2014;28:492-8.

19 Guyton AC. Textbook of medical physiology. 6th edn. Philadelphia: WB Saunders, 1981: 137.

20 Myers T. Anatomy Trains. London, UK: Elsevier Health Sciences, 2010.

21 Starlanyl D, Sharkey J. Healing through trigger point therapy: a guide to fibromyalgia, myofascial pain, and dysfunction. Chichester, England: Lotus Pub, 2013. 